\title{
A brincadeira de papéis sociais e a formação de bases para a apropriação da linguagem escrita pela criança pré-escolar
}

The social role game and the formation of basis for the appropriation of written language by the pre-school child

https://doi.org/10.34112/2317-0972a2020v38n78p35-49

Michelle de Freitas Bissoli ${ }^{1}$

Aline Janell de Andrade Barroso Moraes ${ }^{2}$

RESUMO: A apropriação da cultura escrita pela criança é um processo longo e complexo, que se inicia muito antes de sua entrada na escola. Vigotski postula que o desenvolvimento da capacidade simbólica e o controle de conduta são condições essenciais para o desenvolvimento da capacidade de ler e escrever. Essas capacidades são exercitadas por diferentes atividades, especialmente o brincar de faz-de-conta. Este texto objetiva refletir sobre as relações entre o brincar e o desenvolvimento da linguagem escrita, com base nas contribuições da Teoria Histórico-Cultural. Partimos do pressuposto de que o conhecimento dos professores a respeito da pré-história da escrita pode contribuir para um trabalho pedagógico mais efetivo na formação de leitores e autores.

PALAVRAS-CHAVE: Brincadeira de papéis sociais; pré-história da linguagem escrita; educação infantil.

ABSTRACT: The appropriation of the culture written by the child is a long and complex process, which begins long before their entry into school. Vygotsky postulates that the development of symbolic capacity and the control of their own conduct are essential conditions for the development of reading and writing abilities. These skills are exercised by

1. Universidade Federal do Amazonas, Manaus, Amazonas, Brasil.

2. Secretaria Municipal de Educação, Manaus, Amazonas, Brasil. 
A brincadeira de papéis sociais e a formação de bases para a apropriação da...

different activities, especially make-believe play. This text aims to reflect on the relationship between play and the development of written language, based on the contributions of the Historical-Cultural Theory. We assume that teachers' knowledge about the prehistory of writing can contribute to a more effective pedagogical work in the formation of readers and authors.

KEYWORDS: Social Role Game; prehistory of written language; child education.

\section{INTRODUÇÃO}

Brincar é essencial. Trata-se de um direito de toda criança.

Além disso, brincar compõe o que Vigotski (2012) denomina pré-história da linguagem escrita. Sob essa perspectiva, a aprendizagem da leitura e da escrita requer, necessariamente, que o brincar seja parte da vida da criança. Mas, infelizmente, essa ainda não é uma ideia partilhada por muitas pessoas. E isso tem implicações diretas na forma como a escrita é apresentada e apropriada pelas crianças pequenas.

Embora seja muito comum em nossa sociedade o discurso sobre a necessidade de brincar na infância, sabemos que nem sempre o que se diz reverbera na garantia dos direitos dos meninos e meninas mesmo na Educação Infantil. E, quando refletimos sobre as realidades do brincar nas escolas, é preocupante perceber que, em nome da apropriação precoce e eficiente do ler e do escrever, essa atividade é relegada a segundo plano, sendo substituída por treinos de escrita que também não contribuem para que a criança se torne autora e leitora de textos.

Ora, temos então um duplo equívoco: desconsideramos a importância da brincadeira - e o fato de que ela é, ao lado das interações, um dos eixos das práticas pedagógicas na Educação Infantil (BRASIL, 2010) - e, ao mesmo tempo, ao nos depararmos com um entendimento, baseado no senso comum, de que a linguagem escrita se desenvolve a partir do treino de mãos e dedos, como criticou Vigotski (2012) no início do século passado, percebemos que as crianças não se tornam leitoras e autoras. Como se diz popularmente, descobrimos um santo para cobrir o outro. E acabamos com dois santos descobertos...

Muitas pessoas não percebem que escrever é mais que copiar; ler é mais que decifrar. Trata-se de capacidades que envolvem a necessidade de expressão da criança. $\mathrm{E}$ alguém somente se expressa se tem o que expressar: ideias, sentimentos, descobertas. Mas, se são impedidas de ampliar suas experiências infantis porque sua rotina é marcada pela repetição infindável de letras e sílabas, se não têm oportunidade de interagir, 
brincar, tatear, movimentar-se, conversar, falta-lhes certamente o que escrever. Afinal, a leitura do mundo precede a leitura (e a escrita) da palavra (FREIRE, 1989).

A ideia de que a linguagem escrita possui uma pré-história (VYGOTSKI, 2012), formada pelo desenvolvimento de atividades que a antecedem e preparam a criança para apreender essa capacidade que é tão complexa quanto fundamental para o desenvolvimento da sua inteligência e da sua personalidade, precisa ser melhor conhecida pelos professores e professoras da Educação Infantil e dos Anos Iniciais do Ensino Fundamental. Afinal, a criança que adentra o primeiro ano da segunda etapa da Educação Básica é e será ainda uma criança por muitos anos.

Neste texto, propomo-nos discutir a relação entre o brincar, mais especificamente a chamada brincadeira de papéis sociais, jogo de papéis ou faz-de-conta - que aqui são tomados como sinônimos, com base na perspectiva histórico-cultural -, e a apropriação da linguagem escrita, esperando contribuir para a ampliação desta reflexão.

\section{O PAPEL DO BRINCAR NO DESENVOLVIMENTO HUMANO}

De acordo com os estudos de Leontiev (2014), cada estágio do desenvolvimento da criança é marcado por uma atividade principal. A atividade principal é entendida como aquela em que "[...] ocorrem as mais importantes mudanças no desenvolvimento psíquico da criança dentro da qual se desenvolvem processos psíquicos que preparam o caminho da transição da criança para um novo e mais elevado nível de desenvolvimento" (LEONTIEV, 2014, p. 122). Não se trata necessariamente da atividade para a qual as crianças dedicam mais tempo, mas daquela que apresenta resultados mais profundos e significativos para o seu desenvolvimento integral.

Leontiev (2014) esclarece que, por intermédio da atividade principal, ocorrem as principais mudanças psicológicas na personalidade da criança em cada estágio do seu desenvolvimento, e vários processos psíquicos tomam forma e são reorganizados.

Na idade pré-escolar, a atividade principal da criança é a brincadeira de papéis sociais. Ao brincar de faz-de-conta, meninos e meninas se apropriam de valores, dos usos dos objetos e dos costumes do meio cultural a que pertencem. A característica estruturante dessa atividade é a de que o motivo do brincar se encontra no próprio processo, em seu conteúdo e não em seu resultado, o que dá a ela um caráter de atividade lúdica (LEONTIEV, 2014, p. 119). Isso revela a forma específica pela qual a criança se relaciona com o mundo a sua volta nesse momento da vida. Assim, a criança brinca sem qualquer outro objetivo que não seja o próprio brincar e nele 
A brincadeira de papéis sociais e a formação de bases para a apropriação da...

aprende sobre as pessoas e suas relações, sobre o mundo que a cerca e sobre si mesma. O motivo que mobiliza os seus fazeres durante essa atividade são as sensações, sentimentos e conhecimentos mobilizados na e pela própria atividade.

Considerando essa premissa, qual a relação entre as brincadeiras de papéis e os processos que constituem a base para a apropriação da linguagem escrita? Embora exista um entrelaçamento entre eles, ainda percebemos que existe um certo desconhecimento sobre essa relação quando se trata do trabalho pedagógico desenvolvido com a criança pré-escolar. Para responder a essa questão, nos apoiamos, neste artigo, principalmente nos estudos de Vigotski (2012, 2008, 2014), Leontiev (2014) e Elkonin (1987). Queremos ressaltar que, apesar de alguns desses estudos não tratarem diretamente sobre a relação entre brincar e o processo de apropriação da linguagem escrita pela criança, eles nos oferecem subsídios para compreendermos as conexões entre a atividade principal dos meninos e meninas pré-escolares e a possibilidade de se tornarem capazes de ler e escrever.

Sentimos necessidade de refletir sobre essa relação considerando dois motivos: primeiramente, em razão de a brincadeira de papéis ser a atividade que mais desenvolve a criança pré-escolar, como já mencionamos. Sabendo disso, é contraproducente não garantir um lugar de destaque para essa atividade na prática pedagógica. Em segundo lugar, temos percebido que tarefas comumente propostas nas escolas para a apropriação da linguagem escrita - treinos de escrita e de decodificação e codificação - não têm sentido, mas ocupam grande espaço no seu cotidiano em detrimento do tempo para brincar, como se a escrita fosse a atividade mais importante deste momento, e, talvez, da vida da criança.

A discussão que trazemos aqui é um recorte da nossa pesquisa de mestrado (MORAES, 2015), na qual analisamos a atividade pedagógica do professor e sua relação com o processo de apropriação da linguagem escrita pela criança pré-escolar, a partir da abordagem histórico-cultural.

Muitos são os estudos que evidenciam o papel e a importância do brincar na Educação Infantil. Dentre eles, destacamos as pesquisas de Bomfim (2012), Lazaretti (2016) e Marcolino (2013), que também assumem o referencial teórico histórico-cultural. Trata-se de pesquisas que contribuem para reforçar a importância do brincar na pré-escola como uma atividade fundamental para que as crianças se desenvolvam integralmente, como preconizam os documentos oficiais que norteiam a Educação Infantil em nosso país (BRASIL, 2010). 
Acreditamos que, embora exista o consenso sobre a importância do brincar na Educação Infantil, a sua desvalorização se dá, em grande medida, pelo fato de que muitos conceitos e suas implicações para a prática pedagógica são, ainda, naturalizados pelos professores e professoras, havendo uma ausência de conhecimentos conceituais que esclareçam quais são as especificidades da aprendizagem e do desenvolvimento das crianças nessa etapa e que orientem os fazeres docentes.

Tal fato pode ser justificado pela relação de obviedade que os professores estabelecem com o conhecimento científico que deveria ser o fundamento para o seu trabalho: muitas vezes, essa relação é mediada pela espontaneidade, pela naturalização e pelo economicismo (MELLO, 200o), próprios de atividades que não exigem um nível elevado de consciência. No tocante à questão conceitual e a seus desdobramentos, essa postura, que provém de pouco aprofundamento teórico e de pouca reflexão, cria uma falsa sensação de clareza conceitual, levando muitos professores e professoras a acreditarem que "tudo sempre foi assim" e por isso deve continuar a ser assim (MELLO, 2000). Nesse sentido, de acordo com Mello (2000, p. 71), "ao tratar os conceitos de forma óbvia, ao tomá-los naturalmente, acaba-se por dispensar a busca de seu sentido e significado". Acaba-se, pois, por assumir uma prática pedagógica que toma por base o senso comum e não os conhecimentos acumulados pela ciência - que permitem uma relação consciente com os objetivos do trabalho de educar e com as formas de alcançá-los. E isso valida a reprodução inquestionada de um modus operandi que, depois de tantos anos, continua a caracterizar o trabalho de professores e professoras da Educação Infantil.

A nosso ver, essa ausência de inquietação para entender os fenômenos para além da aparência externa afeta também o entendimento sobre o por que as crianças brincam, sobre quais são os impactos da brincadeira de papéis para o desenvolvimento das crianças e, ainda, dentre outras questões, sobre como esse brincar contribui para que se apropriem da escrita.

Embora os professores sejam profissionais que exercem forte influência sobre o desenvolvimento psíquico da criança, muitas vezes eles não percebem que, em seu trabalho, mobilizam os processos de formação das capacidades cognitivas, afetivas e da personalidade infantis (BISSOLI, 2006). Falta-lhes a mediação de conceitos que os ajudem a tomar consciência da dimensão formativa de seu trabalho e essa ausência tem suas raízes em diferentes aspectos que envolvem o ser professor no Brasil, hoje: as condições de formação inicial e continuada, nem sempre dedicadas às especificidades do ensinar e do aprender na Educação Infantil; a realidade de 
carência material em que desenvolvem seu trabalho nas escolas brasileiras; a desvalorização profissional (BOTH, 2016).

Conforme a abordagem histórico-cultural, na brincadeira de papéis encontram-se as bases para a percepção que a criança pré-escolar tem do mundo a sua volta, que envolve os objetos e as relações humanas, e é justamente essa percepção que alimenta o conteúdo de suas brincadeiras (LEONTIEV, 2014). Nesse contexto, as relações sociais da criança são elevadas pelo brincar, como assevera Elkonin (1987, p. 93, tradução nossa):

No jogo [de papéis, a criança] não só incorpora os conhecimentos infantis sobre a realidade social, mas também os eleva a um nível superior, transmitindo um caráter consciente e generalizado. Através do jogo o mundo das relações sociais, muito mais complexas que as acessíveis à criança em sua atividade lúdica, introduz-se em sua vida e a eleva a um nível significativamente mais alto. Nisso consiste um dos traços essenciais do jogo, nele radica uma das significações mais importantes para o desenvolvimento da personalidade infantil.

A criança brinca de faz-de-conta porque tem necessidade de operar com o mundo dos adultos, de fazer o que eles fazem, de usar os objetos que eles utilizam e de viver o que eles vivem, embora não tenha condições para isso. O brincar é a atividade que permite que a criança consiga imitar a vida adulta e, assim, compreendê-la. Pela brincadeira de papéis a criança sente que tem domínio da realidade e vai tomando consciência de si e das relações humanas, desenvolvendo suas capacidades físicas, cognitivas e afetivas. Podemos dizer que, nesse processo, ela vai se humanizando. Segundo Lazaretti (2016, p. 132), "brincar é representar o homem".

O brincar não desenvolve isoladamente os processos psíquicos das crianças, como o pensamento, a memória, a imaginação e a voluntariedade. Por sua abrangência, essa atividade contribui para o desenvolvimento omnilateral da criança. Para Elkonin,

Sua importância para o desenvolvimento da personalidade do pré-escolar não reside em que nele se exercitem processos psíquicos isolados; inversamente, os processos psíquicos isolados se elevam a uma escala superior graças à qual o jogo desenvolve toda a personalidade da criança pré-escolar, sua consciência. No jogo [de papéis] a criança toma consciência de si mesma, aprende a desejar e a subordinar o seu desejo, 
seus impulsos afetivos passageiros; aprende a atuar subordinando suas ações a um determinado modelo, a uma norma de comportamento (ELKONIN, 1987, p. 99).

A criança aprende a antecipar os resultados de suas ações, a avaliá-los, desenvolvendo um domínio sobre si mesma que é bastante complexo (e necessário para atividades intencionais e conscientes como a leitura e a escrita). Assim, há um equívoco na ideia, ainda presente em muitas escolas da infância, de que o brincar deve acontecer em momentos esporádicos ou para preencher um tempo que sobrou das atividades de rotina. Primeiramente, porque a finalidade da Educação Infantilé propiciar experiências significativas de descoberta do mundo cultural por intermédio das diferentes linguagens, contribuindo para a formação integral das crianças e a brincadeira de papéis contribui para isso. Em segundo lugar, porque a atividade principal da idade pré-escolar, o brincar, é condição para o desenvolvimento da atividade principal da etapa posterior: a atividade de estudo (ELKONIN, 1987). Por isso, ao retirar tempo, espaço e condições para brincar, em busca de antecipar a aprendizagem de conteúdos e, supostamente, o desenvolvimento cognitivo das crianças, demonstra-se, mais uma vez, a falta de conhecimento sobre essa atividade e sobre o próprio desenvolvimento infantil.

Nesse sentido, a brincadeira de papéis é uma das atividades estruturantes do fazer pedagógico na Educação Infantil também porque abre para a criança inúmeras possibilidades de refletir sobre a realidade e de querer saber mais, base fundamental para as suas aprendizagens nos anos iniciais do Ensino Fundamental. Na pré-escola, o brincar não é "só" brincar, mas é ampliar ao máximo as possibilidades de desenvolvimento infantil - da percepção, da atenção, da memória, do pensamento, da linguagem, da imaginação, do planejamento, da convivência com os outros, por exemplo -, construindo as bases para novas e mais complexas aprendizagens. Sua ausência denota que essas bases não serão formadas, prejudicando o desenvolvimento infantil como um todo.

Brincando, a criança desenvolve, ainda, o domínio da conduta e aprende a se autorregular, já que, para representar os papéis sociais, ela precisa ter autocontrole de suas ações, aderindo a normas de comportamento que, fora do faz-de-conta, ainda lhe são difíceis de compreender e praticar. Em consequência desse domínio da conduta, a criança se subordina a regras - inicialmente implícitas, no faz-de-conta e, mais tarde, explícitas, nos jogos com regras - que estão presentes no brincar, mesmo que não tenha consciência disso (VIGOTSKI, 2008); amplia o vocabulário 
A brincadeira de papéis sociais e a formação de bases para a apropriação da...

e a capacidade de comunicação, à medida que dialoga e argumenta com seus pares; expressa sentimentos e emoções.

O brincar de faz-de-conta nos oferece a oportunidade de perceber os significados e sentidos que a criança atribui às relações e papéis sociais representados; possibilita que a criança faça antecipações de ações tendo em vista o comportamento de seus colegas, estimulando a cooperação e o desenvolvimento da capacidade de planejar e de ajudar o outro; permite variadas interações com as pessoas e com os objetos; desenvolve a consciência corporal e a função simbólica da consciência da criança à medida que permite que ela atue simbolicamente, utilizando objetos em lugar de outros nos momentos de representação - capacidades essenciais para a leitura e a autoria de textos escritos.

\section{A BRINCADEIRA DE PAPÉIS E SEU PAPEL NA PRÉ-HISTÓRIA DA ESCRITA}

Como já discutimos, Vigotski (2012) afirma que a linguagem escrita possui uma pré-história fundamental para o seu desenvolvimento. Segundo o autor, o desenvolvimento da linguagem escrita apresenta diferentes momentos, que se constituem pelos gestos, pela fala, pelo desenho e pelo brincar de faz-de-conta. Tais momentos se unem de maneira única por sua essência: embora com características próprias, todas essas atividades desenvolvem a capacidade simbólica da consciência da criança - ou a capacidade de representar a realidade a partir de signos. Por seu intermédio, as crianças podem pensar sobre e representar o que está ausente de seu campo de percepção imediato, suas memórias, suas ideias, seus afetos. Trata-se de uma capacidade bastante sofisticada, especificamente humana. Vigotski (2012, p. 184) enfatiza que "o domínio da linguagem escrita significa para a criança dominar um sistema extremamente complexo de signos simbólicos" e o exercício da representação por intermédio de outras atividades de sua pré-história prepara o caminho para a escrita propriamente dita.

No tocante ao brincar, especificamente, Vygotski (2008, p. 31) admite que "o significado emancipa-se do objeto a que, antes, estava diretamente unido. [...] na brincadeira, a criança opera com o significado separadamente do objeto, mas o significado é inseparável da ação com o objeto real". Assim, uma caneta, para a criança que não está brincando, é apenas uma caneta. Na brincadeira, ela passa a representar um avião, por exemplo. Então, mesmo sabendo que se trata de uma caneta e agindo sobre ela segundo suas propriedades físicas, a criança atribui um sentido diverso ao objeto e o denomina, durante a ação lúdica, como avião. Tal emancipação da 
palavra em relação ao objeto separa significado e sentido. Vigotski (2008, p. 30, grifos nossos) adverte, entretanto, que

[...] Separar a ideia (significado da palavra) do objeto éuma tarefa tremendamente difícil para a criança. A brincadeira é uma forma de transição para isso. Nesse momento em que o cabo de vassoura, ou seja, o objeto, transforma-se num ponto de apoio (pivô) para a separação do significado 'cavalo' do cavalo real, nesse momento crítico, modifica-se radicalmente uma das estruturas psicológicas que determinam a relação da criança com a realidade.

Para além disso, "Do ponto de vista do desenvolvimento, a criação de uma situação imaginária pode ser analisada como um caminho para o desenvolvimento do pensamento abstrato [...]" (VIGOTSKI, 2008, p. 36).

Ora, a emancipação das palavras em relação aos objetos ocorre também quando falamos e escrevemos: atuamos com os significados e sentidos das palavras e não mais com os objetos que elas representam. Para escrever, entretanto, isso se dá de forma mais sofisticada. Combinamos palavras, expressões próprias do texto escrito, uma linguagem diferenciada, para expressar ideias, conhecimentos, sentimentos, em um nível avançado de abstração. Ao escrever, atuamos, como no brincar, a partir da criação de uma situação que pode ser considerada fictícia, em que imaginamos um interlocutor, suas enunciações e desejos, e produzimos o texto tendo em vista nos comunicar com esse alguém ausente.

Mais um elemento nos permite perceber os vínculos entre a brincadeira de papéis e a escrita:

Na brincadeira da idade pré-escolar temos, pela primeira vez, a divergência entre o campo semântico e o ótico. Parece-me ser possível repetir o raciocínio de um pesquisador que diz que, na brincadeira, a ideia separa-se do objeto e a ação desencadeia-se da ideia e não do objeto (VIGOTSKI, 2008, p. 30).

Temos, assim, um pressuposto que demonstra o quanto o brincar exercita uma capacidade necessária ao escrever, ao se tornar autor: a escrita desencadeia-se das ideias e não dos objetos, é abstrata por natureza. De acordo com Vygotski (2014), a linguagem escrita tem uma função toda especial para o desenvolvimento da criança e se diferencia da linguagem oral tanto por sua estrutura como pelo seu funcionamento. Para o domínio da linguagem escrita, a criança necessita de um alto grau 
A brincadeira de papéis sociais e a formação de bases para a apropriação da...

de abstração, já que se "[...] trata de uma linguagem sem entonação, sem expressividade, sem nada do aspecto sonoro. É uma linguagem no pensamento, nas ideias" (VYGOTSKI, 2014, p. 229). É, também, como vimos, uma linguagem marcada pela ausência de um interlocutor: não acontece um encontro físico de quem escreve com a pessoa para quem a escrita está sendo dirigida; toda a relação entre autor e leitor é mediada pelo texto. Essas características da linguagem escrita são suficientes para "[...] modificar por completo todo o conjunto de condições psicológicas que se dão na linguagem oral" (VYGOTSKI, 2014, p. 229). O autor enfatiza que “[...] a linguagem escrita introduz a criança num plano abstrato mais elevado da linguagem, reestruturando com ele o sistema psíquico da linguagem oral estabelecido anteriormente" (2014, p. 230, tradução nossa).

Leontiev (2014) também destaca a capacidade de generalização e a separação entre significado e sentido como essenciais à brincadeira de papéis. De acordo com ele, o brincar é sempre uma atividade generalizada. Ao brincar de faz-de-conta, ao representar cada papel social, a criança não imita uma única pessoa, mas toda uma classe ou grupo de pessoas que desempenham esse papel.

Podemos dizer que a brincadeira de faz-de-conta, ao requerer a atividade generalizada e a separação entre significado e sentido, promovendo o desenvolvimento do pensamento abstrato, coloca em ação capacidades fundamentais para a formação da criança como leitora e autora. Ora, ler é pensar abstratamente sobre realidades apresentadas pela mediação da escrita, fazer generalizações que permitem ao leitor compreender outras realidades a partir daquela que o texto revela. Escrever é, igualmente, elaborar com a linguagem escrita um pensamento a ser expresso para um interlocutor abstrato, que não responde direta e imediatamente ao que comunicamos. É preciso lidar abstrata e generalizadamente com ele, imaginando as interlocuções possíveis. E o que mais fazem as crianças quando criam situações fictícias e, muitas vezes, brincando sozinhas com os objetos, imaginam diálogos completos entre personagens que não existem na realidade?

Ler é, também, perceber que, para além dos significados convencionais das palavras, elas têm sentidos que expressam as ideias, o humor, a ironia, as intenções do autor. É atribuir-lhes sentidos próprios, complementando o texto, interagindo discursivamente com ele. Escrever, por seu turno, é produzir discursos que, pela mediação das palavras, expressem os sentidos que o autor atribui à realidade. Assim, a brincadeira de papéis é fundamental para que capacidades essenciais aos processos de leitura e escrita possam ser exercitadas. 
Embora o estudo da pré-história da linguagem escrita nos permita perceber que ler e escrever possuem uma base simbólica, e que, portanto, essa base deveria ser priorizada ao serem planejadas as atividades que visam a contribuir para o desenvolvimento de leitores e escritores desde a pré-escola, notamos que, nas escolas, as técnicas de escrita das letras se sobrepõem à linguagem escrita como uma forma de representação e de expressão.

Se a escrita tem como função servir de meio para que nos comuniquemos, para que recordemos fatos, para que expressemos sentimentos e ideias, são essas as funções que $o$ contato com a linguagem escrita nas escolas deve privilegiar e engendrar e não os treinos de coordenação motora, discriminação visual e auditiva e a repetição de letras e sílabas isoladas. É importante ressaltar que, ao contrário do que preconiza o senso comum, as crianças vão se apropriando da linguagem escrita não porque já conseguem traçar letras com habilidade, mas porque exercitam a função simbólica brincando, desenhando, pintando, construindo, modelando, conversando e, também, lendo e escrevendo textos reais a destinatários reais, pela mediação da voz e das mãos de seus professores e professoras (MORAES, 2015; MORAES; BISSOLI, 2018). É Vygotski quem indica que "o fator muscular, a motricidade da escrita, desempenha, sem dúvida, um papel importante, mas é um fator subordinado" (VYGOTSKI, 2012, p. 202) a uma atividade do pensamento verbal. Trata-se de uma capacidade complexa desenvolvida à medida que a função social da linguagem escrita pode ser apropriada pelas crianças.

A apropriação da linguagem escrita e a formação das capacidades de leitura e de autoria de textos exige, portanto, uma convivência com textos reais, vivos, lidos e produzidos com e pelas crianças em situações em que são necessários. É preciso que as crianças brinquem, conversem, desenhem e convivam com os textos reais, presentes na sociedade letrada, apreendendo suas funções e características.

Compreendemos, assim, que a Educação Infantil pode contribuir para o desenvolvimento da linguagem escrita criando novas necessidades nas crianças, dentre elas, a de exercitar a função simbólica por intermédio de diferentes atividades e linguagens. Podemos considerar o desenvolvimento da função simbólica da consciência uma das mais importantes formações nessa etapa da escolarização. O contato significativo com os textos que ampliam os referenciais de experiência das crianças - e que, dialeticamente, contribuem também para ampliar e enriquecer suas diferentes formas de expressão, como o desenho e o próprio brincar de faz-de-conta -, são elementos fundamentais para um trabalho que contribua para que as crianças pré-escolares, sem 
A brincadeira de papéis sociais e a formação de bases para a apropriação da...

que precisem ser alfabetizadas, estabeleçam um contato com a linguagem escrita que contribua efetivamente para se tornarem leitoras e autoras de textos. Para aprender a escrever, é preciso aprender a simbolizar e entendemos, com base no exposto, que o brincar é uma das formas privilegiadas para essa aprendizagem.

\section{CONSIDERAÇÕES FINAIS}

A brincadeira de papéis tem um papel essencial no desenvolvimento da criança pré-escolar. Embora tenhamos destacado, neste texto, as capacidades desenvolvidas pelo brincar que contribuem para a apropriação da escrita, nosso objeto de reflexão, é preciso ressaltar que todas essas capacidades e processos que o brincar desenvolve na criança são importantes para o seu desenvolvimento omnilateral.

Cabe destacar que, para que o brincar contribua para o desenvolvimento das crianças em todo o seu potencial, condições materiais para que ele aconteça e se amplie precisam ser garantidas nas escolas, além das reflexões contínuas dos professores e professoras. É necessária uma prática intencional em relação ao brincar na pré-escola, o que requer não o didatizar nem o relegar ao espontaneísmo.

Entendemos que os professores têm papel fundamental nesse contexto, por serem aqueles que, de forma direta, medeiam as situações vivenciadas pelas crianças, oferecendo recursos materiais e tempo na rotina diária, e por poderem observar as referências que meninos e meninas já têm sobre os papéis sociais que representam, para que possam ampliá-los. É nessa ampliação de referências que está a centralidade do papel do professor no tocante ao desenvolvimento do brincar. E, para essa ampliação, as visitas a diferentes espaços da comunidade (padaria, salão de beleza, restaurante etc.), como evidencia Marcolino (2013), são uma possibilidade para que as crianças estendam cada vez mais o que sabem sobre os diferentes papéis sociais, seus fazeres, seus instrumentos. A leitura literária, por seu turno, também constitui uma forma de ampliar os modos de percepção da realidade pelas crianças, além de possibilitar o contato significativo com a escrita. As personagens e suas vivências podem compor os argumentos do brincar das crianças, enriquecendo sua imaginação e suas possibilidades de criação de situações fictícias. Outras possibilidades podem ser engendradas a partir do conhecimento aprimorado sobre a atividade principal da criança pré-escolar.

Porém, é importante reconhecer que não cabe somente aos professores garantir as condições para que o brincar realmente aconteça. É preciso que as secretarias 
de educação municipais conheçam a importância do brincar e garantam recursos financeiros para que sejam adquiridos os materiais necessários para a criação de espaços para o brincar, além de incentivarem que o tempo para o faz-de-conta seja assegurado. Ressaltamos essa situação, tendo em vista que é comum que se diga que não há recursos para esse fim, porém, é possível constatar, por outro lado, a disponibilidade de recursos financeiros para a aquisição de sistemas apostilados de ensino e livros didáticos para a Educação Infantil, demonstrando incoerência em relação às especificidades das formas de aprender e de ensinar nesta etapa e ao que preconizam os documentos oficiais.

Finalmente, em vez de dedicar tempo para os treinos de escrita - como se isso garantisse a apropriação da linguagem escrita pela criança -, insistimos que, diante de tudo o que discutimos sobre as capacidades essenciais que os pequenos desenvolvem por intermédio do faz-de-conta, o brincar deve ser assegurado nas práticas pedagógicas das pré-escolas, considerando a formação humana e o desenvolvimento da expressão das crianças, também pela escrita.

\section{REFERÊNCIAS}

ARENA, D. B. Unidades e funções em linguagem: implicações pedagógicas da teoria histórico-cultural. In: CAÇÃO, M. I.; MELLO, S. A.; SILVA, V. P. (Org.). Educação e Desenvolvimento Humano: Contribuições da abordagem histórico-cultural para a educação escolar. Jundiaí: Paco Editorial, 2014. BISSOLI, M. F. Por uma pedagogia de formação da personalidade da criança: o professor como um especialista em desenvolvimento infantil. In: BRITO, Luiz Carlos Cerquinho de (Org.). Processos de aprendizagem e construção do conhecimento. Manaus: CEFORT/EDUA, 2006.

BOMFIM, J. C. O papel do brincar na apropriação da linguagem escrita. 2012. 111 f. Dissertação (Mestrado em Educação) - Faculdade de Filosofia e Ciências, Universidade Estadual Paulista, São Paulo, 2012.

BRASIL. Ministério da Educação. Secretaria de Educação Básica. Diretrizes Curriculares Nacionais para a Educação Infantil. Brasília: MEC/SEB, 2010.

ELKONIN, D. B. Problemas psicológicos do jogo na idade pré-escolar. In: DAVÍDOV, V.; SHUARE, M. (Org.). La Psicologia Evolutiva y Pedagógica en la URSS. Moscou: Editorial Progresso, 1987.

FREIRE, P. A importância do ato de ler: em três artigos que se completam. São Paulo: Autores Associados, 1989.

LAZARETTI, L M. A brincadeira de papéis sociais e o ensino sistematizado. In: MARTINS, L. M.; ABRANTES, A. A.; FACCI, M. G. D. (Org). Periodização histórico-cultural do desenvolvimento psíquico: do nascimento à velhice. Campinas: Autores Associados, 2016.

LEONTIEV, A. O desenvolvimento do psiquismo. São Paulo: Centauro, 2004. 
A brincadeira de papéis sociais e a formação de bases para a apropriação da...

LEONTIEV, A. N. Os princípios psicológicos da brincadeira pré-escolar. In: VIGOTSKI, L. S.; LURIA, A. R.; LEONTIEV, A. N. Linguagem, desenvolvimento e aprendizagem. São Paulo: Ícone, 2014.

MARCOLINO, S. A mediação pedagógica na educação infantil para o desenvolvimento da brincadeira de papéis sociais. 2013. 185 f. (Doutorado em Educação) - Universidade Estadual Paulista/UNESP, Marília, 2013.

MELLO, S. A. Linguagem, consciência e alienação: o óbvio como obstáculo ao desenvolvimento da consciência crítica. Marília: Unesp-Marília-Publicações, 2000.

MORAES, Aline Janell de Andrade Barroso. A atividade pedagógica do professor e o processo de apropriação da linguagem escrita pela criança pré-escolar: um estudo a partir da abordagem histórico-cultural. 2015. 241 f. Dissertação (Mestrado em Educação) - Universidade Federal do Amazonas, Manaus, 2015.

VIGOTSKI, L. S. A brincadeira e o seu papel no desenvolvimento psíquico da criança. Revista Virtual de Gestão de Iniciativas Sociais, Rio de Janeiro, UFRJ, n. 8, abr. 2008.

VYGOTSKI, L. S. Obras escogidas. v. 2. Madrid: Antônio Machado Livros, 2014.

VYGOTSKI, L. S. Obras escogidas. v. 3. Madrid: Antônio Machado Livros, 2012.

\section{SOBRE AS AUTORAS}

Michelle de Freitas Bissoli é graduada em Pedagogia pela Universidade Estadual Paulista "Júlio de Mesquita Filho" (UNESP/Campus Marília), tem Mestrado e Doutorado em Educação pela mesma Universidade. É professora/ pesquisadora da Universidade Federal do Amazonas (UFAM). Tem experiência na área de Formação de Professores e Educação Infantil, com pesquisa nos seguintes temas: Teoria Histórico-Cultural; Literatura Infantil; Formação de leitores; Formação de professores para a Educação Infantil. Atualmente, coordena a pesquisa Formação de Professores para as práticas de leitura literária nas pré-escolas públicas de Manaus: a apropriação da cultura escrita na abordagem histórico-cultural, financiada pela Fundação de Amparo à Pesquisa do Estado do Amazonas (FAPEAM).

E-mail:mibissoli@ufam.edu.br.

Aline Janell de Andrade Barroso Moraes é graduada em Pedagogia pela Universidade Federal do Amazonas (UFAM), tem Mestrado e cursa Doutorado em Educação pela mesma Universidade, com Bolsa CAPES. É professora da Secretaria Municipal de Educação (SEMED/Manaus). Tem experiência na área de Formação de Professores e Educação Infantil, com pesquisa nos seguintes temas: Teoria Histórico-Cultural; Literatura Infantil; Formação de leitores; 
Formação de professores para a Educação Infantil. Atualmente, participa como estudante na pesquisa Formação de Professores para as práticas de leitura literária nas pré-escolas públicas de Manaus: a apropriação da cultura escrita na abordagem histórico-cultural, financiada pela Fundação de Amparo à Pesquisa do Estado do Amazonas (FAPEAM).

E-mail: aline.janell@bol.com.br.

Recebido em 02 de agosto de 2019 e aprovado em 25 de novembro de 2019. 